\title{
Prevention of Hypertension at Intubation: A Controlled Study of Sublingual Nifedipine
}

Nirmal Kumar Gyawali

Author Info:

Dr. Nirmal Kumar Gyawali

Consultant Anesthesiologist,

Western Hospital Nepalgunj, Nepal

\section{Corresponding Author:}

Email/Contact:

nkgyawali@gmail.com

9858021961

\begin{abstract}
Background: Hypertension and tachycardia-induced after laryngoscopy and intubation can be prevented by various methods like deep inhalation anesthesia, intravenous opioids, topical intravenous lidocaine, intravenous adrenergic blocking drugs and pretreatment with antihypertensive.

Methods: It is a randomized controlled double-blind prospective study of two groups consisting of 30 patients in each group. Group A was the control group and group B were Nifedipine group who were pretreated with Nifedipine. This study aimed to assess the effectiveness of pretreatment with nifedipine in the prevention of the hypertensive response to laryngoscopy and endotracheal intubation in normotensive patients undergoing elective surgery.
\end{abstract}

Result: Sublingual nifedipine was significantly effective in decreasing systolic and diastolic blood pressure produced by laryngoscopy and tracheal intubation, but its role in decreasing pulse rate was not significant.

Conclusion: Nifedipine is useful to prevent laryngoscopy and intubation induced hemodynamic response.

Keywords: Intubation, laryngoscopy, hypertension, Pharmacology of Nifedipine, sublingual

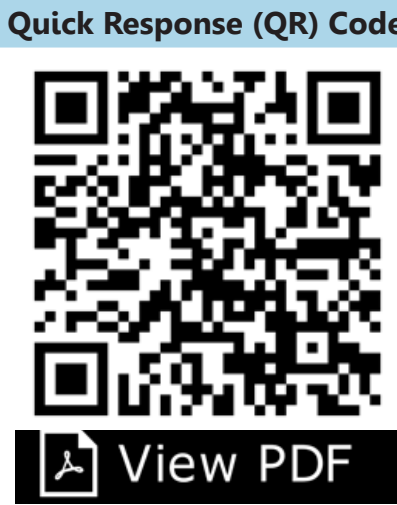

Scan Me for Full Text

\section{Article Info}

Received: 2 November 2019; Accepted: 10 March 2020; Published Online: 11 March 2020 How to cite this article in Vancouver Style?

Gyawali NK.Prevention of Hypertension at Intubation: A Controlled Study of Sublingual Nifedipine. Europasian J Med Sci.2020;2(1):37-40. https://doi.org/10.46405/ejms.v2i1.33

\section{Disclaimer:}

Conflict of Interest: None Declared;

Source of Support: Nil

Copyright: ( $\subset 2020$ by author(s). This is an open access article distributed under the terms of the Creative Commons Attribution International License 4.0 (http://creativecommons.org/licenses/ by/4.0/) which permits unrestricted use, distribution, and reproduction in any medium, provided the original work is properly cited.

Publisher's Note:

The Europasian Journal of Medical Sciences (EJMS) is an official Journal of Nirvana Psychosocial Care Center \& Research Institute (www. nirvanapscc.com) and published by it. The Journal as well as publisher remain neutral with regards to any jurisdictional claims in any published articles, its contents and the institutional affiliations of the authors.

\section{INTRODUCTION}

Transient hypertension and tachycardia are commonly associated with laryngoscopy and tracheal intubation. ${ }^{1,2}$ These must be considered as potent noxious stimuli because of their effects on autonomic nervous activity. Hypertension and tachycardia may be inconsequential in healthy patients but detrimental to those with ischaemic heart disease or increased intracranial pressure and have been the subject of many studies to determine an effective method of prevention. Various attempts have been made to block this stress response but most of the attempts are only partially successful. ${ }^{3,4}$

Nifedipine is a calcium channel entry blocker that produces dilatation of both peripheral and coronary arteries. $^{5}$ There are different classes of 
calcium channel entry blocker, the classification proposed by the WHO divide the calcium channel entry blockers into two groups: group A consist of calcium entry blocker selective for slow calcium channel derivative e.g. verapamil and derivatives like dihydropyridine (DPN), nifedipine, nicardipine, nimodipine, nitrendipine and diltiazem. Group B consists of calcium channel entry blocker, non-selective for slow calcium channel e.g.: diphenyl piperzazeios, bepridil, perhexiline. The general objective of the study was to find out the incidence of laryngoscopy and intubation induced hypertension and the role of nifedipine in the prevention of intubation and laryngoscopy induced hypertension and tachycardia.

\section{MATERIALS AND METHODS}

Methods This is an interventional study (Randomized controlled trial) conducted in Western Hospital and Research Centre Nepalgunj in the year 2014/2015. Informed consent was obtained from each of the patients included in the study. Study was conducted in 60 patients of both sexes of ASA classification I and II in the age range of 20-60 years and weight between 35 to $70 \mathrm{~kg}$ undergoing elective surgeries. Informed consent was obtained in all instances. Preanesthetic examination of the patients was done and patients were kept nil orally after $11 \mathrm{pm}$ the day before surgery.

In the morning, half an hour before operation patients were brought in the pre-anesthetic room and blood pressure was recorded by an assistant. An intravenous line was established with 18 gauze cannula and the ringer's lactate infusion was started. Patient selection was done by lottery method to decide whether or not to give nifedipine. The anesthetic assistant gave $5 \mathrm{mg}$ nifedipine capsule to group $B$ patient ten minutes before induction. The capsule was pierced with needle and contents squeezed out under tongue. Group-A patients were given nothing after the recording of $\mathrm{BP}$ and Pulse rate patients were sent to the operation room. In operation room intubation done by the investigator. Intravenous pethidine $0.5 \mathrm{mg} / \mathrm{kg}$ was given before induction and Induction was done with thiopental $6 \mathrm{mg} / \mathrm{kg}$, Succinylcholine $1.5 \mathrm{mg} /$ $\mathrm{kg}$ and patients were intubated with an appropriate sized endotracheal tube. During induction and intubation patients showing any unusual effect (coughing, vomiting) were grouped as stressful laryngoscopy and they were not included in the study. Student's t-test for paired observations was used for analysis within the group and an unpaired t-test was used for analysis between the groups. $\mathrm{P}<0.05$ was considered statistically significant. The patients with a history of hypertension and cardiovascular disease, patients above 60 years and below 20 years, and the patients showing stressful features during Induction (coughing, vomiting) were excluded from this study

\section{RESULTS}

The demographic characteristics of the patients under study are shown in the table below. There was no significant difference in the mean age and weight of the patients in the control group compared to the Nifedipine group. Changes in cardiovascular variables in the control group and Nifedipinegroup before pretreatment and after laryngoscopy.

Systolic blood pressure increased after laryngoscopy and intubation in control patients as well as in nifedipine treated patients, however the increase in systolic blood pressure was significantly less in nifedipine treated patients $(p<0.05)$.

Similarly, diastolic blood pressure also increased in both the groups after intubation but this rise in diastolic bp was significantly lesser in the nifedipine treated group compared to the control group $(p<0.05)$. There was an increase in pulse rate after laryngoscopy in both the groups but no significant difference existed between the two groups ( $p>0.05)$.
Table 1: Demographics characteristics

\begin{tabular}{lll}
\hline Characteristic & Control group & Nifedipine group \\
\hline Sex & 8 & 5 \\
Male & 22 & 25 \\
Female & $39.93 \pm 3.55$ years & $38.83 \pm 2.15$ years \\
Weight (Mean \pm SD) & $44.57 \pm 5.3 \mathrm{~kg}$ & $42.73 \pm 2.5 \mathrm{~kg}$
\end{tabular}




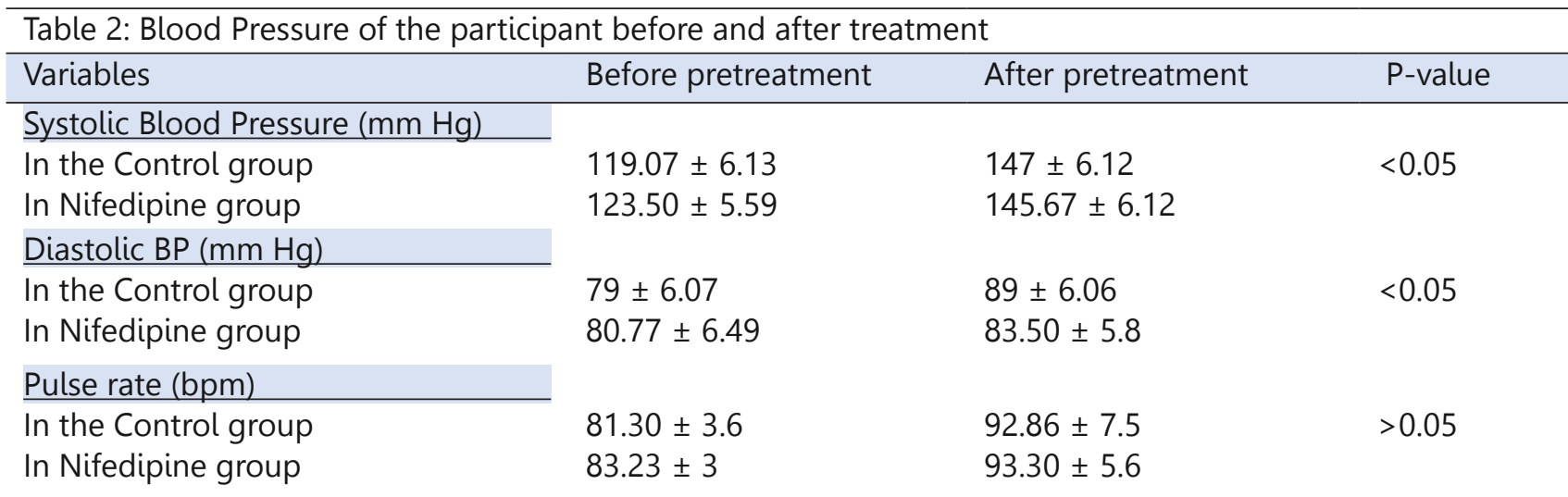

\section{DISCUSSION}

Reflex increase in cardiovascular responses to laryngoscopy and intubation are tachycardia and hypertension which is common during induction of anesthesia. This is due to a positive increase in sympathoadrenal activity and a definite increase in plasma adrenaline, non-adrenaline and dopamine level in patients undergoing endotracheal intubation. ${ }^{6}$ The magnitude of change of clinical parameters in MAP and cardiac rhythm paralleled the significant increase in catecholamines. ${ }^{7}$ An increase in blood pressure associated with tracheal intubation may be dangerous and may cause complication including pulmonary edema. These facts are derived from studies during different forms of inhalation anesthesia..$^{-11}$ and are interpreted as being the result of reflex sympathoadrenal stimulation. The severity of this response in normotensive patients is less certain. The purpose of our study was to measure the cardiovascular response to laryngotracheal stimulation in healthy patients without cardiovascular diseases to avoid myocardial ischemia at intubation. In our study, we found nifedipine was affective to attenuate cardiovascular response to intubation and laryngoscopy. Nifedipine is an antagonist of Calcium channel through the slow channel of the cell membrane and it is an effective treatment for mild to moderate hypertension as well as stable, variant and unstable angina. ${ }^{12,13}$ Our study shows that sublingual nifedipine attenuated the increase in systolic and diastolic blood pressure produced by laryngoscopy and tracheal intubation, but its role in decreasing pulse rate was not significant. $A$ similar study was done by N Kumar in a woman with pregnancy induced hypertension scheduled for caesarian section under general anesthesia. They found sublingual nifedipine effective in attenuating the hypertensive response to laryngoscopy and intubation. ${ }^{14}$ Nifedipine versus fentanyl to prevent the pressure response to tracheal intubation study done by Abdel Razek et al. ${ }^{15}$ They concluded that nifedipine was better than fentanyl in blocking the pressure response. Peripheral vasodilation and the resulting decline in blood pressure produced by Nifedipine activates baroreceptors leading to increased peripheral sympathetic nervous system activity most often manifesting as elevated heart rate. This increased nervous system activity counters the direct negative ionotropic and chronotropic effects of the nifedipine. A study by Fenkal et al indicated that nifedipine has greater efficiency than hydralazine in achieving control BP in severe preeclampsia. ${ }^{6}$

\section{CONCLUSION}

The nifedipine was found to be effective in attenuating hemodynamic responses following laryngoscopy and intubation. An increase in Blood pressure and tachycardia to laryngotracheal stimulation are present in all patients which is of short duration but can give a detrimental effect on the patients with cardiovascular diseases so prevention of this hemodynamic response should be practiced during induction and intubation.

\section{REFERENCES}

1. Millar FA, Dally FG. Acute hypertension during induction of anaesthesia and endotracheal intubation in normotensive man. BJA 1970;42:61824. https://doi.org/10.1093/bja/42.7.618 CrossRef | Full Text

2. Prys RC, Creene LT, Meloche R, Foex P. Studies of Anaesthesia in relation to hypertension and endotracheal intubation. BJA 1971;43:531-47. https://doi.org/10.1093/bja/43.6.531 CrossRef | PubMed | Full Text 
3. Stoelting RK. Attenuation of blood pressure response to laryngoscopy and tracheal intubation with sodium nitroprusside. Anaesthesia and Analgesia 1979;58:116-19. https://doi.org/10.1213/00000539197903000-00011 CrossRef | Full Text

4. Curran J, Crowley M, Sullivan G. Droperidol and endotracheal intubation: attenuation of pressor response to laryngoscopy and tracheal intubation. Anaesthesia 1980; 35:290-94.https://doi. org/10.1111/j.1365-2044.1980.tb05099.x CrossRef | PubMed | Full Text

5. Braunwald E. Mechanism of action of calcium channel blocking agents. N Engl J Med 1982 ; 307:1618-27. https://doi.org/10.1056/NEJM198212233072605 CrossRef | PubMed | Full Text

6. Stoelting RK. Circulatory changes during direct laryngoscopy and tracheal intubation: influence of duration of laryngoscopy with or without prior lidocaine. Anaesthesiology 1977;47:381-4. https:// doi.org/10.1097/00000542-197710000-00012 CrossRef | PubMed | Full Text

7. Russell W, Drew S, Morris R, Frewin D. Changes in plasma catecholamine concentrations during endotracheal intubation. BJA. Elsevier 2017;53:83739. https://doi.org/10.1093/bja/53.8.837 CrossRef | Full Text

8. Reid LC, Brace DE. Irritation of the respiratory tract and its reflex effect upon the heart. Surg Gynaecol Obstet. 1940;70:157-62. Google Scholar

9. Burstein $\mathrm{CL}$, Lopinto FJ, Newman W. Electrocardiographic studies during endotracheal intubation.1. Effects during usual routine technics. Anesthesiology. 1950 March, 11(2)224-37. https:// doi.org/10.1097/00000542-195003000-00011 CrossRef | Full Text
10. Connell H, Dalgleish JG, Downing JW. General anesthesia in mothers with severe pre-eclampsia/ eclampsia. Br J Anaesth 1987;59:1375-80. https:// doi.org/10.1093/bja/59.11.1375 CrossRef | Full Text

11. Lawes EG, Downing JW, Duncan PW, Bland B,Lavies N, Gane GA. Fentanyl-droperidol supplementation of rapid sequence induction in the presence of severe pregnancy-induced and pregnancy-aggravated hypertension. Br j Anaesth. 1987;59:1381-91. https:// doi.org/10.1093/bja/59.11.1381 CrossRef | PubMed | Full Text

12. Laderballe PO, Mikkelsen E. Acute and Chronic effects of Nifedipine in arterial hypertension. EJCP 1982;307:1618-27.

13. Beer N, Gallegos I, Cohen A, Klein N, Sonnenblick E, Frishman W. Efficacy of sublingual nifedipine in the acute treatment of systemic hypertension. Chest 1981;79:571-74. https://doi.org/10.1378/ chest.79.5.571 CrossRef | Full Text

14. Kumar N,Bhtra YK, Bala I, Gopalan S. Nifedipine attenuates the response to tracheal intubation in pregnancy induced hypertension. Canadian journal of Anesthesia 1993; 40 (4):329-33. https://doi. org/10.1007/BF03009631 CrossRef | Full Text

15. Razel A.Nifedipine versus fentanyl to prevent the pressure response to tracheal intubation. Middle East J. Anaesthesiol1995.

16. Fenkal K, Fenakal G, Appelman Z, Lurie S, Katz Z, Shoham Z. Nifedipine in the treatment of severe preeclampsia. ObstectGynecol1991;77(3) : :331-37. PubMed 